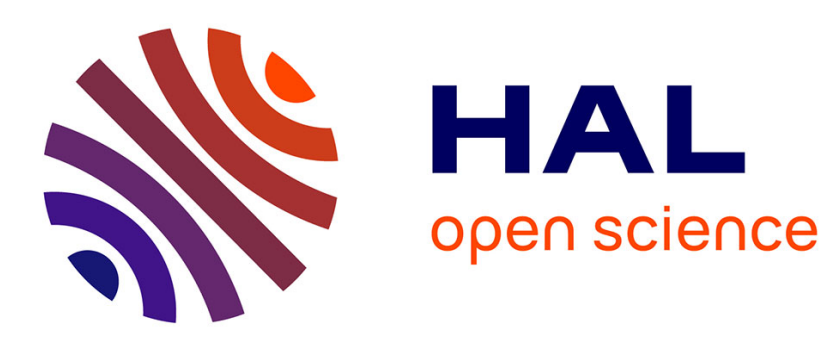

\title{
Innovation in the Shadow of Patent Litigation
}

Yann Ménière, Sarah Parlane

\section{- To cite this version:}

Yann Ménière, Sarah Parlane. Innovation in the Shadow of Patent Litigation. Review of Industrial

Organization, 2008, 32 (2), pp.95-111. 10.1007/s11151-008-9167-y . hal-00397130

\section{HAL Id: hal-00397130 \\ https://hal-mines-paristech.archives-ouvertes.fr/hal-00397130}

Submitted on 19 Jun 2009

HAL is a multi-disciplinary open access archive for the deposit and dissemination of scientific research documents, whether they are published or not. The documents may come from teaching and research institutions in France or abroad, or from public or private research centers.
L'archive ouverte pluridisciplinaire HAL, est destinée au dépôt et à la diffusion de documents scientifiques de niveau recherche, publiés ou non, émanant des établissements d'enseignement et de recherche français ou étrangers, des laboratoires publics ou privés. 


\title{
Innovation in the shadow of patent litigation
}

\author{
Yann Ménière and Sarah Parlane*
}

April 17, 2008

\begin{abstract}
We analyze non-cooperative $R \& D$ investment by two firms that already hold patents that they can assert against each other with probabilistic success. The market structure results from stochastic innovation and patent litigation. Depending on the level of infringement fees, we highlight positive and negative effects of litigation threats on innovation. We define an appropriate regulatory structure of infringement fees that will implement socially efficient R\&D investments in the case of symmetric and asymmetric patent portfolios.
\end{abstract}

*We are grateful to Lawrence White, Katharine Rockett, Suzanne Scotchmer and Jean Tirole and two anonymous referees for their comments and corrections. 
Dr, Yann Ménière, Cerna, Ecole des mines de Paris, 60 Boulevard Saint Michel, 75272 Paris cedex 06, France. Email: meniere@ensmp.fr

Dr. Sarah Parlane, School of Economics, University College Dublin, Belfield, Dublin 4, Ireland. Email: Sarah.Parlane@ucd.ie. 


\section{Introduction}

Patents are meant to create incentives to invest in $R \& D$ by conferring property rights, including legal exclusivity on innovations. Yet in some cases patents may also represent an impediment for innovators. As products embody increasing numbers of patented components, especially in sectors such as semiconductors and computer hardware and software, it is often difficult for an innovator to anticipate exactly what patents she might be infringing. Therefore innovators face a threat of patent litigation by other patent owners even though they did not knowingly imitate any patented technology.

The eBay v. MercExchange case in the U.S. illustrates the problem. MercExchange entered the online auction market in 1995, but failed commercially and exited in 2000. In the meantime it had filed minor patents for online auctions and for direct-buy software. The auction giant eBay had developed similar tools and therefore contacted MercExchange in 2000 to buy the patents. MercExchange refused and decided instead to sue eBay for infringement in 2001. Such litigation reallocates innovation profits between firms that engaged into similar technology paths ex ante. Therefore it affects incentives to innovate and affect R\&D efficiency.

In practice patent owners generally seek an injunction when their patent covers a component of a larger product. An injunction allows the patent owner potentially to obtain much more than what the patented component is actually worth, because it allows the patent owner to hold-up the production and commercialization of the entire product until a settlement is reached (Lemley and 
Shapiro, 2006). This use of an injunction is increasingly seen as detrimental to innovation (FTC, 2003; Lemley and Shapiro, 2006). The U.S. draft Patent Reform Act of 2005 aimed to limit access to injunctions, and called for a renewed definition of infringement penalties. ${ }^{1}$ In this context, in May 2006 the U.S. Supreme Court overturned the Court of Appeals for the Federal Circuit decision to issue a permanent injunction against eBay. In July 2007 the District Court issued an order denying the injunction and ruling that monetary damages were a sufficient remedy in that case. In parallel, a Patent Reform bill is being considered in the Congress that would require that damages awarded more accurately reflect the actual harm caused by a patent infringement when the infringing product embodies a combination of several patented inventions.

In this paper, we study the interplay between hold-up litigation and investments in $R \& D$, and propose a policy instrument to implement efficiency. We consider firms that develop innovations in the shadow of each other's patent portfolios. In the absence of litigation threats firms play a standard $R \& D$ race in which they tend to overinvest. But this over-investment can eventually reverse as the threat of patent litigation erodes the incentives to innovate. We use this setting to evaluate the efficiency of firms' investments and address the problem of the optimal definition of infringement penalties. We find both proand anti-innovation effects of overlapping patent portfolios, depending on the level of infringement penalties. We show that the possibility of hold-up can

\footnotetext{
${ }^{1}$ The Patent Reform Act states that "the Court should conduct an analysis to ensure that a reasonable royalty [...] is applied only to that economic value properly attributable to the patent's specific contribution over the prior art."
} 
actually facilitate the implementation of efficient R\&D investments, provided that infringement fees are small enough and the firms' patent portfolios not too asymmetric.

The paper is structured as follows: We review the related literature in the next Section. We then introduce the model, our definition of social efficiency and the decentralized equilibrium in Sections 3 and 4 . We study the case of symmetric firms in Section 5 before moving to the asymmetric case in Section 6. Section 7 concludes.

\section{Related literature}

Large overlapping patent portfolios are frequent in electronics and computer hardware and software, where they form "patent thickets" that firms have to navigate (Shapiro, 2001). ${ }^{2}$ This situation results from a dramatic increase of firms' patenting propensity during the last two decades (Hall and Ziedonis, 2001; Shapiro, 2001; FTC, 2003; Graham and Mowery, 2003). ${ }^{3}$ It can be seen as the outcome of a prisoner's dilemma (Bessen, 2003), whereby firms reply to patent infringement threats by filing more patents, which they can use as counter threats. It generates transaction costs and double marginalization issues that reduce incentives to innovate. ${ }^{4}$ It also generates legal uncertainty that, as we

\footnotetext{
${ }^{2}$ More than "90,000 patents generally related to microprocessors are held by more than 10,000 parties", while "approximately 420,000 semiconductor and system patents [are] held by more than 40,000 parties" (FTC, 2003).

${ }^{3}$ The number of patents per million of U.S. dollars invested in R\&D has doubled between 1982 and 1992 in the U.S. semiconductor industry (Hall and Ziedonis, 2001). Graham and Mowery (2003) find similar results for incumbent software firms during the 1990's.

${ }^{4}$ According to an industry executive, new semiconductor manufacturers must for instance pay $\$ 100$ million to $\$ 200$ million to license out-of-date manufacturing technologies (Hall and
} 
show in this paper, can affect $R \& D$ competition in various ways.

When innovation is cumulative, it is well established that the risk of hold-up by an upstream patent owner can deter investments in downstream innovations (Scotchmer, 1991; Green and Scotchmer, 1995; Bessen, 2004). Green and Scotchmer (1995) show that this problem can be overcome if firms successfully negotiate a licensing agreement before R\&D costs are sunk. However such ex ante contracts are actually quite rare (Anand and Khanna, 2000), because of information asymmetries with respect to existing patents (Reitzig et al., 2007), or on the cost and value of the future innovation (Bessen, 2004; Llobet, 2003).

We extend the analysis of patent hold-up to the case of competing firms that own their respective patent portfolios and that invest simultaneously in R\&D. This approach can be related to an early paper by Fershtman and Kamien (1992), in which firms engage in parallel patent races for complementary innovations. Our model is, however, closer to Bessen (2003) and Bessen and Hunt (2007) in that it takes into account the possibility of patent litigation between former R\&D competitors. Their papers consider as endogenous both patent filing and $R \& D$ decisions to establish the existence of a prisoner's dilemma between firms. By contrast, we consider exogenous patent portfolios, study their impact on market structure and R\&D efficiency, and characterize optimal infringement penalties.

In the literature on patent litigation some papers focus on the definition of infringement penalties. Schankerman and Scotchmer (2001, 2005) and Anton and

Ziedonis, 2001). 
Yao (2006) discuss whether applying the standard "lost profits" doctrine can deter infringement effectively when the patent protects a stand-alone innovation. ${ }^{5}$ However, this approach does not apply well to the case of multi-components technologies. Lemley and Shapiro (2006) focus on situations of hold-up when the patent covers one element of a broader technology. They defend the view that an injunction should not be applied to multi-component technologies when infringement was not voluntary, and emphasize the importance of infringement penalty definition. Our paper complements theirs by proposing a rule for defining optimal infringement penalties.

\section{The model}

We consider a model where two firms (firm 1 and firm 2) each undertake R\&D investments to develop imperfectly substitutable products that will use the intellectual property that is embodied in its existing patents (and possibly in the existing patents of its rival as well). To keep matters simple we assume that firms have symmetric R\&D functions: firm $i(i=1,2)$ invests $\frac{\delta}{2} x_{i}^{2}$ to be successful with probability $x_{i}$ where $\delta>1$.

Each firm holds patents that it can assert against its competitor. With probability $\theta_{i}(i=1,2)$ firm $j$ 's $(j \neq i)$ product is judged to be infringing one of firm $i$ 's patents by a court of law. The probabilities $\theta_{1}$ and $\theta_{2}$ are common knowledge so that each firm is able to anticipate perfectly the issue of litigation.

\footnotetext{
${ }^{5}$ The "lost profits" doctrine defines the infringement damage as the profits lost by the patent owner because the infringer imitated her invention.
} 
We normalize the demand side by assuming that the monopoly profit is equal to $1\left(\pi^{M}=1\right)$ and the competitive profit $\left(\pi^{C}\right)$ is given by

$$
\pi^{C}=\frac{1-\alpha}{2}
$$

where $\alpha \in[0,1]$ is a measure of product market's competitiveness given the characteristics of outputs 1 and 2 .

The R\&D and litigation stages can result in various market structures. Consider first that both firms have developed a product. The following states of nature may then arise:

- With probability $\left(1-\theta_{1}\right)\left(1-\theta_{2}\right)$ the court rejects both infringement claims. The firms become independent competitors on the product market, and each of them gets the competitive profit $\pi^{C}$.

- With probability $\theta_{i}\left(1-\theta_{j}\right)$ the court upholds firm $i$ 's infringement claim but rejects firm $j$ 's. In this case firm $i$ controls an essential technology input for firm $j$ 's activity (at least from a legal viewpoint). It is thus entitled to evict its opponent from the market and enjoy a monopoly position. It gets the monopoly profit $\pi^{M}$ while its opponent gets nothing.

- With probability $\theta_{1} \theta_{2}$ infringement is reciprocal. Then each firm controls a key technology input for its competitor's activity. A joint-profit maximizing solution consists of one firm's dropping out of the market and recovering half of the other firm's monopoly profit through a licensing 
agreement. ${ }^{6}$

Assume firm $i(i=1,2)$ successfully innovates, while its opponent fails and claims $i$ 's new product infringes one of its patents.

- With probability $\left(1-\theta_{j}\right)$ the court rejects the claim, and the innovator fully enjoys the monopoly profit $\pi^{M}$.

- With probability $\theta_{j}$ the court upholds the claim. Then the innovator has to pay an infringement penalty $r_{j}$ to firm $j$.

The question we address is whether there exists a reasonable, non-negative infringement penalty $r_{i}(i=1,2)$ that leads to efficient R\&D investments. By reasonable we mean here that $r_{i}$ must satisfy the ex-post voluntary participation and therefore technically require $r_{i} \leq 1$ for $i=1,2$.

To summarize the above, let $\pi_{i}^{k}$ denote firm $i$ 's expected revenue when firm $k$ innovates. We have

$$
\pi_{i}^{i}=1-\theta_{j} r_{j}
$$

and

$$
\pi_{j}^{i}=\theta_{j} r_{j}, \quad i, j=1,2 \text { and } j \neq i
$$

When both firms innovate the expected profit to firm $i$ (denoted $\pi_{i}^{12}$ ) is given

\footnotetext{
${ }^{6}$ Alternatively, one could imagine that firms successfully negotiate a cross-licensing agreement whereby each of them pays a per-unit royalty to its competitor on the product market. Depending on the level of royalty, such agreement could yield any profit level between competitive profits and monopoly profits. This alternative way of solving the double infringement case would not modify our results. For simplicity we thus keep as a working assumption the case in which firms share the monopoly profit.
} 
by

$$
\pi_{i}^{12}=\theta_{i}\left(1-\frac{1}{2} \theta_{j}\right)+\pi^{C}\left(1-\theta_{i}\right)\left(1-\theta_{j}\right), \quad i, j=1,2 \text { and } j \neq i
$$

\section{Efficient investment and non-cooperative so- lution}

We define efficient $R \& D$ investments as those that maximize the expected profits of a single joint venture company aggregating the $R \& D$ capacities of both firms. This definition is consistent with the standard result indicating that the hold-up problem can be solved ex ante if the patentee and the infringing innovator strike a licensing or joint venture agreement before the $R \& D$ costs are sunk (Green and Scotchmer (1995), Llobet (2003), Bessen (2004)). In our model a joint venture would make a monopoly profit if at least one product is developed. The corresponding expected profit is given by

$$
J P=1-(1-x)^{2}-\delta x^{2}
$$

It is maximized by $x^{*}=1 /(1+\delta)$. Having defined efficient R\&D investments, we now turn to the equilibrium investments in the absence of an ex ante agreement. The expected profit to firm $i$ when it invests is given by:

$$
\Pi_{i}\left(x_{i}, x_{j}\right)=x_{i}\left(1-x_{j}\right) \pi_{i}^{i}+x_{j}\left(1-x_{i}\right) \pi_{i}^{j}+x_{i} x_{j} \pi_{i}^{12}-\frac{\delta}{2}\left(x_{i}\right)^{2}
$$


If it chooses not to invest, it can nonetheless extract some revenue using its portfolio. Its reservation payoff is then given by:

$$
\Pi_{i}^{R}=x_{j} \pi_{i}^{j}=x_{j}\left(1-\pi_{j}^{j}\right)
$$

Firm $i$ selects $x_{i}^{*}\left(x_{j}\right)$ such that

$$
x_{i}^{*}\left(x_{j}\right) \in \arg \max _{x_{i}} \Pi_{i}\left(x_{i}, x_{j}\right),
$$

and the firm chooses $x_{i}^{*}\left(x_{j}\right)$ if $\Pi_{i}\left(x_{i}^{*}\left(x_{j}\right), x_{j}\right) \geq \Pi_{i}^{R}$ and 0 otherwise.

\section{Symmetric patent portfolios}

As a first step we solve the model for an industry in which firms hold symmetric patent portfolios $\left(\theta_{1}=\theta_{2}=\theta\right)$. Such symmetry can be viewed as featuring an industry in which incumbent firms have been accumulating patent portfolios at the same pace over time. Let $\pi_{M}$ denote the profit of a firm that innovated while the other failed $\left(\pi_{M}=\pi_{i}^{i}\right)$. Let $\pi_{D}$ denote the profit of a firm if both firms innovated (with $\pi_{D}=\pi_{i}^{12}=\pi_{j}^{12}$ ). We have:

$$
\begin{gathered}
\pi_{M}=1-\theta r \\
\pi_{D}=\theta\left(1-\frac{1}{2} \theta\right)+\frac{1}{2}(1-\alpha)(1-\theta)^{2} .
\end{gathered}
$$

Profit $\pi_{M}$ is obviously decreasing in $\theta$ since hold-up deprives the single in- 
novator from a part of her monopoly profit. By contrast it can be checked easily that $\pi_{D}$ is increasing in $\theta$, which is less intuitive. This is due to the effect of patent infringement on the market structure. Any successful infringement claim transforms a competitive product market into a monopoly. Hence stronger patents increase the expected payoff of the firms when both innovate. ${ }^{7}$

Lemma 1: There exists a unique symmetric equilibrium in which both firms invest so as to achieve an innovation success probability $x^{S}$ which is given by

$$
x^{S}=\frac{\pi_{M}}{1+\delta-\pi_{D}} .
$$

Proof: See Appendix 1.

Strikingly, the equilibrium innovation success probability $x^{S}$ is increasing in $\pi_{M}$ and $\pi_{D}$. Since $\theta$ decreases $\pi_{M}$ but increases $\pi_{D}$, how changes in $\theta$ affect $x^{S}$ is ambiguous. Overall we have

$$
\text { sign of } \frac{d x^{S}}{d \theta}=\operatorname{sign} \text { of } \alpha(1-\theta) \pi_{M}-r\left(1+\delta-\pi_{D}\right) \text {. }
$$

It follows directly that the effect of the litigation threat on $R \& D$ investments depends on the level of penalty $r$, and that $\mathrm{R} \& \mathrm{D}$ expenditure can be increasing in the litigation threat.

Lemma 2: Let $r_{0}=2 \alpha /(1+2 \delta+\alpha)$. For any $r \geq r_{0}$, then $\frac{d x^{S}}{d \theta}<0$. For

\footnotetext{
${ }^{7}$ Note here that the positive effect of $\theta$ on $\pi_{2}$ still holds if we assume that the firms share less than the monopoly profit in case of double infringement.
} 
any $r<r_{0}$, there is a unique $\theta_{r} \in[0,1]$ such that $\frac{d x^{S}}{d \theta} \gtreqless 0 \Leftrightarrow \theta \leq \theta_{r}$.

Proof: See Appendix 2.

Investments are decreasing in $\theta$ when $r \geq r_{0}$, and they are inverse U-shaped with respect to $\theta$ otherwise. A high infringement penalty $r$ means that holdup can deprive a single successful innovator from a large part of her monopoly profit. This negative effect dominates the market structure effect, and an increase in $\theta$ depresses investments. This case can be viewed as a free-riding pattern. Each firm has an incentive to let its competitor innovate and to sue it afterwards instead of developing its own innovation at the risk of being sued by its competitor.

If, by contrast, $r$ is small, a successful innovator does not lose much if he is held up by an unsuccessful innovator. Hence the market structure effect dominates, and a higher $\theta$ actually reinforces the incentives to innovate. This finding implies that, for appropriate (low) levels of infringement penalty, the existence of a litigation threat can actually reinforce $R \& D$ investments in comparison with a situation where there is no legal uncertainty (e.g., where $\theta=0$ ).

We now examine how these effects interplay with the efficiency of R\&D. Note first that the optimal level of investment, which is based on an optimal innovation innovation success probability $x^{*}=1 /(1+\delta)$, is equal to the equilibrium investment if there is no litigation threat $(\theta=0)$ and firms make no profit if they compete in the product market $(\alpha=1)$. It follows that the additional profits due to imperfect competition on the product market $(\alpha<1)$ yield socially excessive R\&D investments at equilibrium. In other words, firms start 
an $R \& D$ race in the absence of a litigation threat.

Lemma 3: On the assumption that $\theta=0$, the equilibrium investment is such that the innovation success probability $x^{S}=x^{*}$ if $\alpha=1$ and $x^{S}>x^{*}$ if $\alpha<1$.

Against this background of excessive investments, the existence of a litigation threat might work either as an accelerator or as a brake. If the infringement penalty is too weak, legal uncertainty actually reinforces the $\mathrm{R} \& \mathrm{D}$ race, contrary to what intuition suggests. By contrast, a relatively high infringement penalty might be sufficient to balance over-incentives to innovate by creating a freeriding pattern. Proposition 1 below states that this is possible under some conditions.

Proposition 1: For any $\alpha \in[0,1]$ there is unique $\theta(\alpha)$ where for any $\theta \geq \theta(\alpha)$ it is possible to implement first-best investments through an adequate transfer $r^{*} \in[0,1]$.

We have $\theta(0)=\frac{1}{2(1+\delta)}, \theta(1)=0$ and $\frac{d \theta}{d \alpha}<0 .{ }^{8}$ The infringement penalty is such that (for any $\theta>0$ )

$$
\begin{gathered}
\theta r^{*}=x^{*} \pi_{D} \\
\Leftrightarrow r^{*}=\frac{\theta(2-\theta)+(1-\alpha)(1-\theta)^{2}}{2 \theta(1+\delta)} .
\end{gathered}
$$

Proof: Appendix 3.

\footnotetext{
${ }^{8}$ The expression for $\theta(\alpha)$ can be found in Appendix 3 .
} 
Figure 1 here

The figure above illustrates proposition 1. Equation (7) expresses the optimal balance between free-riding and a patent race. It requires that, conditional on the successful development of an innovation by its opponent, a firm's expected profit from a pure hold-up strategy equals its expected profit from investing efficiently in R\&D. To guarantee $r^{*}<1$, litigation threats must be sufficiently high. As $\theta$ becomes negligible, both the hold-up and the duopoly rents fall, and firms overinvest even if $r=1$. This implies that a strong litigation threat might be not only useful, but also necessary to tame $\mathrm{R} \& \mathrm{D}$ races in sectors where product competition is mild.

Lemma 4: The optimal infringement penalty $r^{*}$ is non-increasing in $\alpha, \delta$, and $\theta$.

When the litigation threat is such that the first-best level of investment can be obtained, the infringement penalty must be calculated according to equation (8). Lemma 4 summarizes the properties of this efficient penalty. The infringement penalty should be low when competition in the product market is intensive and when $R \& D$ is costly, because in this case the $R \& D$ race is moderate. Lemma 4 also states that the optimal penalty should decrease as the litigation threat accentuates. This denotes the fact that at equilibrium the threat of litigation generates a free-riding pattern rather than additional incentives to innovate. In this context, and as indicated in equation (7), the probability of infringement 
and the infringement penalty substitute for each other to maintain the optimal level of expected hold-up profit.

\section{Asymmetric patent portfolios}

Assume now that firms hold asymmetric patent portfolios $\left(\theta_{1} \neq \theta_{2}\right)$. Following our interpretation of patent portfolios as resulting from the firms' histories, we describe the asymmetric portfolio case as representing an incumbent (with the larger portfolio of patents) and a competitor that entered the industry more recently. Without loss of generality, let firm 1 refer to the firm holding a stronger portfolio $\left(\theta_{1}>\theta_{2}\right)$. Let $r$ be the share of a single innovator's profit left to her opponent in the event of a successful infringement claim. Two outcomes can arise in equilibrium depending on whether the parameters $\theta_{1}, \theta_{2}, \delta$ and $r$ satisfy the inequality given below:

$$
\frac{\pi_{2}^{2}}{\pi_{2}^{2}+\pi_{2}^{1}-\pi_{2}^{12}}>\frac{\pi_{1}^{1}}{\delta} .
$$

Lemma 5: For each given values of the parameters $\theta_{1}, \theta_{2}, \delta$ and $r$ the equilibrium is unique. It such that both firms invest in $R \mathscr{E} D$ if and only if (9) holds. Otherwise it is such that only firm 1 invests in R\&D.

Proof: See Appendix 4.

The inequality (9) does not hold when $\theta_{1} r \rightarrow 1$ and $\delta$ is sufficiently high. 
Two difficulties arise under asymmetric portfolios. First they induce asymmetric investment strategies even though the firms have identical R\&D functions. Since efficiency requires that both firms invest the same amount, this is a factor of inefficiency. Moreover, strongly asymmetric portfolios can completely dissuade the firm with a weak portfolio from undertaking $R \& D$. Then the portfolio works as a barrier to entry.

Proposition 2: Provided discrimination is possible, setting $r_{1}^{*}$ and $r_{2}^{*}$ such that:

$$
\begin{gathered}
\theta_{i} r_{i}^{*}=x^{*}\left\{\pi_{i}^{12}+\frac{\delta}{\delta-1}\left[\theta_{j}-\theta_{i}\right]\right\} \\
\Leftrightarrow r_{i}^{*}=\frac{\delta \pi_{j}^{12}-\pi_{i}^{12}}{\theta_{i}\left(\delta^{2}-1\right)}, \quad i, j=1,2 i \neq j,
\end{gathered}
$$

implements an efficient equilibrium.

The values $r_{1}^{*}$ and $r_{2}^{*}$ are such that $r_{1}^{*}<r_{2}^{*}$ and such that the firm with the weakest portfolio has greater expected monopoly rents.

Proof: The efficient investment forms a pooling equilibrium if and only if it solves both best response functions:

$$
\left\{\begin{array}{l}
\delta x^{*}=\left(1-\theta_{2} r_{2}\right)-x^{*}\left[1-\theta_{2} r_{2}+\theta_{1} r_{1}-\pi_{1}^{12}\right], \\
\delta x^{*}=\left(1-\theta_{1} r_{1}\right)-x^{*}\left[1-\theta_{1} r_{1}+\theta_{2} r_{2}-\pi_{2}^{12}\right] .
\end{array}\right.
$$

Solving for $r_{1}$ and $r_{2}$ leads to (11). The proof of the second point is straightforward.

The infringement fees that restore R\&D efficiency are comparable with the 
optimal fee of Proposition 1. Although they are now different for each firm, they are similarly decreasing with the strength of the litigator's portfolio, the cost of $\mathrm{R} \& \mathrm{D}$, and the intensity of market competition.

The expected rent of a patent holder depends once again on the duopoly profits that each firm would make, except that it is now corrected by the difference in the strength of the two firms' property rights. As in the symmetric case, the optimal penalty should decrease as the litigation threat accentuates. This implies that the firm with the stronger portfolio gets less than its expected duopoly profits conditional on investing efficiently while the firm with the weakest portfolio gets more. The amount added or deducted from the duopoly rents is proportional and inversely correlated to the cost of $\mathrm{R} \& \mathrm{D}(\delta)$.

Since we must have $r_{i}^{*} \in[0,1]$, the parameters $\left(\theta_{1}, \theta_{2}\right)$ for which $r_{1}^{*}$ and $r_{2}^{*}$ are well defined are such that $\theta_{i} \in\left[L\left(\theta_{j}\right), U\left(\theta_{j}\right)\right]$ with

$$
U\left(\theta_{j}\right)=\frac{2 \delta \theta_{j}+(\delta-1)(1-\alpha)\left(1-\theta_{j}\right)}{1+\delta-\alpha(\delta-1)\left(1-\theta_{j}\right)}
$$

and

$$
L\left(\theta_{j}\right)=\frac{2 \delta \theta_{j}+(\delta-1)(1-\alpha)\left(1-\theta_{j}\right)}{2 \delta^{2}+\delta-1-\alpha(\delta-1)\left(1-\theta_{j}\right)}
$$

for $i=1,2$ and $j \neq i$. It is obvious that these boundaries define a non-empty interval. Appendix 5 analyzes the functions $U(\theta)$ and $L(\theta)$ in greater detail. Figure 2 (below) gives a visual representation of the interval where $\theta_{1}$ and $\theta_{2}$ 
must lie for an efficient equilibrium to exist.

Figure 2 here

It clearly shows that even with discriminatory fees, efficiency cannot be reached when the patent portfolios are strongly asymmetric. Put differently, the efficiency result obtained for symmetric portfolios is robust only to the introduction of limited asymmetries, on the condition that fees can be tailored as a function of each firm's portfolio.

\section{Conclusion}

The threat of patent hold-up is generally deemed as an impediment to innovation in some industries. In this paper we investigate whether it can be used to balance socially excessive investments when two firms compete in $R \& D$ under the reciprocal threat of patent litigation. We consider a situation where the market structure is determined successively by the probabilistic outcomes of $R \& D$ and patent litigation. In this context we characterize infringement fees that allow efficient $R \& D$ investments in the overall $R \& D$ game.

Depending on the level of infringement fees, we find that the reciprocal threat of patent hold-up can either reinforce incentives to innovate or reduce total R\&D investments. The first effect is due to the positive impact of patent litigation on industry concentration. It dominates when infringement fees are low. As infringement fees increase, it is outweighed by the risk that an innovator will 
be deprived of part of its profits by an opportunistic patent holder. In this case the reciprocal threat of hold-up creates a free-riding pattern whereby each firm prefers to let its competitor develop an innovation and then sue it.

We show that optimal R\&D investment can be implemented by tuning the infringement fees so that the free-riding effect dominates. This solution can be implemented under some conditions, namely when infringement is sufficiently likely and when portfolios are close to symmetric.

High infringement probabilities facilitate the implementation of efficient R\&D investments because they increase the investments' sensitivity to the infringement fee. Since both infringement likelihood and infringement fees then reduce incentives to innovate, maintaining the correct level of incentives requires that infringement fees be decreasing in the strength of the infringed patent portfolio. When patent portfolios are symmetric across the industry, this implies that infringement royalties should be lower when the patent portfolios overlap to a greater extent. We find that this result can be extended to weakly asymmetric portfolios on the condition that the fees can be differentiated. However, when the patent portfolios are strongly asymmetric, there is no reasonable fee that can implement efficiency. The firm with the stronger portfolio therefore invests excessively and deters its competitor. 


\section{Appendix}

\section{Appendix 1: Proof of Lemma 1}

The reaction functions are given by

$$
x_{i}\left(x_{j}\right)=\max \left\{\frac{\pi_{M}-x_{j}\left(1-\pi_{D}\right)}{\delta}, 0\right\}
$$

$i=1,2$ and $j \neq i$.

The reaction functions are downward sloping since $\left(1-\pi_{D}\right)>0$. Moreover,

since $\frac{\pi_{M}}{\delta}<\frac{\pi_{M}}{1-\pi_{D}}$ no asymmetric equilibrium in which a firm invests $\frac{\pi_{M}}{\delta}$ while the other invests 0 is possible. The best reply functions cross once and the symmetric equilibrium described in the proposition is unique. In addition, plugging back the best reply into firm $i^{\prime}$ s profit leads to

$$
\max _{x_{i}} \Pi^{i}=\Pi_{R}^{i}+\frac{\delta}{2}\left[x_{i}\left(x_{j}\right)\right]^{2}>\Pi_{R}^{i}
$$

Thus the participation constraints holds strictly

\section{Appendix 2: Proof of Lemma 2}

Claim: Given any $\theta \in[0,1]$, there exists a unique $r_{\theta}$ such that $\frac{d x^{s}}{d \theta} \geq 0 \Leftrightarrow$ $r \frac{<}{>} r_{\theta}$.We have $\frac{d r_{\theta}}{d \theta}<0$.

Proof: The sign of $\frac{d x^{s}}{d \theta}$ is given by the following function:

$$
F(r, \theta)=\alpha(1-\theta) \pi_{M}-r\left(1+\delta-\pi_{D}\right) .
$$


We have

$$
F(0, \theta)=\alpha(1-\theta) \geq 0
$$

and

$$
F(1, \theta)=\alpha(1-\theta)^{2}-(1+\delta)+\pi_{D}<0,
$$

since $\pi_{D}<\frac{1}{2}$ and $(1+\delta) \geq 2$. The function $F($.$) is continuous in r$. Thus for each $\theta$ there exists at least one $r_{\theta}$ such that $F\left(r_{\theta}, \theta\right)=0$. Finally since

$$
\frac{\partial F}{\partial r}=\pi_{D}-\theta(1-\theta) \alpha-(1+\delta)<0
$$

$r_{\theta}$ is unique. Since $\frac{\partial F}{\partial \theta}=-\alpha \pi_{M}<0$ we have $\frac{d r_{\theta}}{d \theta}=-\left.\frac{\frac{\partial F}{\partial \theta}}{\frac{\partial F}{\partial r}}\right|_{r=r_{\alpha}}<0$. Thus $r(\theta)<r(0) \equiv r_{0}$

Consequently, the above one-to-one relationship implies that for any given $r<r_{0}$ there exists a unique $\theta_{r}$ such that $\frac{d x^{s}}{d \theta} \geq 0 \Leftrightarrow \theta \leq \theta_{r}$.

\section{Appendix 3: Proof of Proposition 1.}

It is possible to implement the socially efficient investment associated with the innovation success probability $x^{S}=x^{*}$ if and only if there exists a unique $r^{*} \in[0,1]$ that satisfies

$$
\theta(1+\delta) r^{*}=\theta\left(1-\frac{\theta}{2}\right)+\frac{(1-\alpha)}{2}(1-\theta)^{2}
$$

We have an equality of the form $A r^{*}=B$ where $A$ and $B$ are non-negative. Hence $r^{*}$ is non-negative. All that remains is to identify the set of parameters 
$(\theta, \alpha)$ such that $r^{*} \leq 1$. Consider the following function

$$
F(\theta, \alpha)=\theta\left(1-\frac{\theta}{2}\right)+(1-\theta)^{2} \frac{(1-\alpha)}{2}-\theta(1+\delta) .
$$

There exists a unique $r^{*} \leq 1$, implementing socially efficient investments, if and only if the parameters $\theta$ and $\alpha$ are such that $F(\theta, \alpha) \leq 0$. We have

$$
F(0, \alpha) \geq 0
$$

and

$$
F(1, \alpha)<0
$$

Since $\frac{\partial F}{\partial \theta}<0$, there exists a unique $\theta(\alpha)$ such that $F(\theta(\alpha), \alpha) \equiv 0$ and such that $F(\theta, \alpha) \leq 0$ for all $\theta \geq \theta(\alpha)$.

Specifically we have

$$
\theta(\alpha)=\frac{\sqrt{(\delta+1-\alpha)^{2}+\alpha(1-\alpha)}-(\delta+1-\alpha)}{\alpha} \forall \alpha>0
$$

and $\theta(0)=\frac{1}{2(\delta+1)}$. Finally, since $\frac{\partial F}{\partial \alpha}<0$, we have $\frac{d \theta}{d \alpha}<0$.

\section{Appendix 4: Proof of Lemma 5}

In the asymmetric case, the reaction curves are given by

$$
\delta x_{1}=\pi_{1}^{1}-x_{2} S_{1}\left(\theta_{1}, \theta_{2}\right)
$$


and

$$
\delta x_{2}=\pi_{2}^{2}-x_{1} S_{2}\left(\theta_{2}, \theta_{1}\right)
$$

where

$$
S_{i}\left(\theta_{i}, \theta_{j}\right)=\pi_{i}^{i}+\pi_{i}^{j}-\pi_{i}^{12}
$$

and where $\pi_{i}^{j}$ and $\pi_{i}^{12} i, j=1,2$ are defined by (1), (2), and (3). To establish the results stated in Lemma 5 we proceed as follows: First we show that the reaction functions are downward sloping. Second, we show that if there is an interior solution, it is unique. We fully characterize it. Last we show that there exists configurations of parameters such that $x_{2}=0$ in equilibrium.

- The reaction functions are downward sloping.

It is straightforward to verify that $S_{1}\left(\theta_{1}, \theta_{2}\right) \geq 0$ so that the first reaction function is downward sloping. For any given $\theta_{j}(j=1,2) S_{2}(.,$.$) is linear in \theta_{i}$. Let $a=\frac{1}{2}\left(1-\alpha\left(1-\theta_{2}\right)\right)$ and $b=\frac{1}{2}\left(1+\alpha\left(1-\theta_{1}\right)\right)$. For $r \in[0, a]$, we have $\frac{\partial S_{2}}{\partial \theta_{2}}<0, \frac{\partial S_{2}}{\partial \theta_{1}}>0$ and thus

$$
S_{2}\left(\theta_{2}, \theta_{1}\right)>S_{2}\left(\theta_{2}, \theta_{2}\right)>0
$$

For $r \in[a, b]$, we have $\frac{\partial S_{2}}{\partial \theta_{2}}<0, \frac{\partial S_{2}}{\partial \theta_{1}}<0$ and therefore $S_{2}\left(\theta_{2}, \theta_{1}\right)>S_{2}(1,1)>$ 0 . Finally for $r \in[b, 1]$, we have $\frac{\partial S_{2}}{\partial \theta_{2}}>0, \frac{\partial S_{2}}{\partial \theta_{1}}<0$ and thus $S_{2}\left(\theta_{2}, \theta_{1}\right)>$ $S_{2}(0,1)>0$. Thus we always have $S_{2}\left(\theta_{2}, \theta_{1}\right)>0$ so that the second reaction function is also downward sloping.

- If interior, the solution is unique. 
Consider a situation where we have

$$
\frac{\pi_{1}^{1}}{\pi_{1}^{1}+\pi_{1}^{2}-\pi_{1}^{12}}>\frac{\pi_{2}^{2}}{\delta} \text { and } \frac{\pi_{2}^{2}}{\pi_{2}^{2}+\pi_{2}^{1}-\pi_{2}^{12}}>\frac{\pi_{1}^{1}}{\delta}
$$

In that case, there is at least one interior equilibrium. In equilibrium (15) and (14) hold so that

$$
x_{2}=\frac{\pi_{1}^{1}}{S_{1}\left(\theta_{1}, \theta_{2}\right)}-x_{1} \frac{S_{2}\left(\theta_{2}, \theta_{1}\right)}{\delta} .
$$

and

$$
x_{2}=\frac{\pi_{2}^{2}}{\delta}-x_{1} \frac{S_{2}\left(\theta_{2}, \theta_{1}\right)}{\delta} .
$$

Firm 1's reaction function is steeper than firm 2's (when setting $x_{2}$ on the vertical axis) since

$$
\delta^{2}>S_{1}\left(\theta_{1}, \theta_{2}\right) S_{2}\left(\theta_{2}, \theta_{1}\right){ }^{9}
$$

Therefore, any equilibrium where $x_{1}>0$ and $x_{2}>0$ is unique. Let $x_{i}^{A S}$ denote firm $i^{\prime} \mathrm{s}$ innovation success probability, we have

$$
x_{i}^{A S}=\frac{\delta \pi_{i}^{i}-\pi_{j}^{j}\left[\pi_{i}^{i}+\pi_{i}^{j}-\pi_{i}^{12}\right]}{\delta^{2}-\left[\pi_{i}^{i}+\pi_{i}^{j}-\pi_{i}^{12}\right]\left[\pi_{j}^{j}+\pi_{j}^{i}-\pi_{j}^{12}\right]}, \quad i, j=1,2, i \neq j,
$$

where $\pi_{i}^{j}$ and $\pi_{i}^{12} i, j=1,2$ are defined by (1), (2), and (3). Plugging back the reaction function into a firm's profit leads to

$$
\max _{x_{i}} \Pi^{i}=\Pi_{R}^{i}+\frac{\delta}{2}\left[x_{i}\left(x_{j}\right)\right]^{2}>\Pi_{R}^{i} \text { for } i=1,2 .
$$

\footnotetext{
${ }^{9}$ Indeed, we have $S_{1}\left(\theta_{1}, \theta_{2}\right) S_{2}\left(\theta_{2}, \theta_{1}\right)<1-\left(\theta_{1} r_{1}-\theta_{2} r_{2}\right)^{2}<1$ and $\delta>1$.
} 
Thus the participation constraint is satisfied.

- For some values of the exogenous parameters, the equilibrium is such that $x_{2}=0$. However we always have $x_{1}>0$.

Since

$$
\frac{\pi_{1}^{1}}{\pi_{1}^{1}+\pi_{1}^{2}-\pi_{1}^{12}}>\frac{\pi_{2}^{2}}{\delta}
$$

there is no equilibrium with $x_{1}=0$.

To guarantee that the reaction curves cross at a point where $x_{2}>0$ we must have

$$
\frac{\pi_{2}^{2}}{\pi_{2}^{2}+\pi_{2}^{1}-\pi_{2}^{12}}>\frac{\pi_{1}^{1}}{\delta}
$$

Depending on the values of $\theta_{1}, \theta_{2}, \delta$ and $r$ the above inequality may or may not hold. For instance let $\theta_{1}=1, \theta_{2}=0.5, r=0.98$ and $\alpha=1$. For any $\delta>6.7$ we have $x_{2}>0$ in equilibrium and for any $\delta \leq 6.7$ we have $x_{2}=0$ in equilibrium.

Appendix 5: Analysis of the functions $U(\theta)$ and $L(\theta)$.

It is obvious to show that $U(\theta)>L(\theta)$. We have

$$
\text { sign of } \frac{d U}{d \theta}=2 \delta+(1-\alpha)+\delta^{2}(1+\alpha)>0 .
$$

Then $U(0)>0$ and

$$
U(\theta)>\theta \Leftrightarrow(\delta-1)\left[1-\alpha(1-\theta)^{2}\right]>0 .
$$


We have

$$
\operatorname{sign} \text { of } \frac{d L}{d \theta}=\delta^{2}(4 \delta-(1-\alpha)(2 \delta+1))+(1-\alpha)\left(4 \delta^{2}-1\right)>0 \text {. }
$$

Then $L(0)>0$ and there exists a unique $\theta^{\prime}$ such that $L\left(\theta^{\prime}\right)=\theta^{\prime}$. The former result can be established considering that $L(\theta)=\theta$ if and only if

$$
2 \delta \theta+\theta-(1-\alpha)-\alpha \theta(1-\theta)=0 .
$$

The left-hand side is an increasing function so that only one $\theta^{\prime}$ solves the equality. Figure 2, in the text, summarizes the above findings.

\section{References}

[1] Anand, B.N. \& Khanna, T. (2000). The Structure of Licensing Contracts. Journal of Industrial Economics, 48, 103-135

[2] Anton, J. \& Yao, D. (2006). Finding 'Lost' Profits: An equilibrium analysis of patent infringement penalties. Journal of Law, Economics and Organizations, 23, 186-207

[3] Bessen, J. (2003). Patent Thickets: Strategic Patenting of Complex Technologies. Research on Innovation Working Paper, http://www.patentmatics.org/pub2004/pub8g.pdf

[4] Bessen, J. (2004). Holdup and Licensing of Cumulative Innovation with Private Information. Economic Letters, 82, 321-326 
[5] Bessen, J. \& Hunt, R. (2007). An Empirical Look at Software Patents. Journal of Economics \& Management Strategy, 16, 157-189.

[6] Federal Trade Commission (2003). To Promote Innovation: A Proper Balance of Competition and Patent Law and Policy. http://www.ftc.gov/opa/2003/10/cpreport.htm.

[7] Fershtman, C. \& Kamien, M. I. (1992). Cross Licensing of Complementary Technologies. International Journal of Industrial Organization, 10, 32948.

[8] Graham, S.J. \& Mowery, D.C. (2003). Intellectual Property Protection in the U.S. Software Industry. (In Cohen, W.M. \& Merrill, S.A. (Eds.), Patents in the Knowledge-Based Economy (pp. 219-254). National Research Council.)

[9] Green, J.R. \& Scotchmer, S. (1995). On the Division of Profit in Sequential Innovation. RAND Journal of Economics, 26, 20-33.

[10] Hall, B.H. \& Ziedonis, R.H. (2001). The Patent Paradox Revisited: an Empirical Study of Patenting in the US Semiconductor Industry, 19791995. RAND Journal of Economics, 32, 101-128.

[11] Lemley, M.A. \& Shapiro, C. (2006). Patent Holdup and Royalty Stacking. Stanford Law School Working Paper No. 324, http://faculty.haas.berkeley.edu/shapiro/stacking.pdf

[12] Llobet, G. (2003). Patent Litigation When Innovation Is Cumulative. International Journal of Industrial Organization, 21, 1135-57. 
[13] Reitzig, M., Henkel, J. \& Heath, C. (2007). On Sharks, Trolls, and Their Patent Prey-Unrealistic Damage Awards and Firms' Strategies of 'Being Infringed'. Research Policy, 36, 134-154.

[14] Schankerman, M. \& Scotchmer, S. (2001). Damages and Injunctions in Protecting Intellectual Property. RAND Journal of Economics, 32, 199220.

[15] Schankerman, M. \& Scotchmer, S. (2005). Still Looking for Lost Profits: the Case of Horizontal Competition. University of California at Berkeley Institute of Business and Economics Research Working Paper No. E05344

[16] Scotchmer, S. (1991). Standing on the Shoulders of Giants: Cumulative Research and the Patent Law. Journal of Economic Perspective, 5, 2941.

[17] Shapiro, C. (2001). Navigating the Patent Thicket: Cross-Licenses, PatentPools, and Standard-Setting. Innovation Policy and the Economy, 1, $119-150$. 